\title{
Effect of Transplanting Dates and Spacing on Yield Attributing Character, Productivity and Economics of Potato Cultivation Through True Potato Seed (TPS) Technology
}

\author{
Debashish Sen ${ }^{1}$, Amitava Rakshit ${ }^{2}$, Narayan Chandra Sarkar ${ }^{3}$, \\ Dulal Chandra Ghosh ${ }^{4}$, Subir Kumar Bardhan Roy \\ ${ }^{1}$ Department of Natural Resource Management, College of Hort. \& Forestry, CAU, Pasighat, \\ Arunachal Pradesh, India \\ ${ }^{2}$ Department of Soil Science, Institute of Agriculture, BHU, Varanasi, Uttar Pradesh, India \\ ${ }^{3}$ Department of Agronomy, School of Agril. Science and Rural Development, NU, Medziphema, \\ Nagaland, India \\ ${ }^{4}$ Department of Agronomy, Institute of Agriculture, Visva-Bharati, Sriniketan, West Bengal, India \\ ${ }^{5}$ AE-697, Salt lake city, Kolkata, West Bengal, India
}

Received: 24 April 2009. Accepted: 20 October 2009.

\begin{abstract}
A field experiment in split plot design was conducted during the rabi season of 2001-02 and 2002-03 at Potato Research and Seed Multiplication Farm, Anandapur, West Midnapore, West Bengal to study the effect of dates of transplanting and spacing on yield attributing character, productivity and economics of potato cultivation through true potato seed (TPS) technology. The highest number of tubers per plant was recorded in early transplanted (December 3) crop, while, crop spacing did not produce any significant differences in recording tuber number per plant. Early established crop also produced significantly higher tuber weight per plant as compared to intermediate (December 11) and late (December 19) transplanted crops and widely spaced $(60 \times 15 \mathrm{~cm})$ crop recorded higher weight of tuber per plant as compared to the narrowly spaced crop. Early transplanting and wider spacing also showed its superiority in respect of recording harvest index of potato. As such, early transplanted and densely planted crops produced significantly higher yield of seedling tuber, marketable tuber and total tuber than their counterparts. Though cost of production of early transplanted and closely spaced crop was higher, but net profit and return per rupee investment was also higher in those cases.
\end{abstract}

Key-words: TPS, potato, yield attributing character, productivity, economics.

\section{Introduction}

Potato (Solanum tuberosum L.), a high value marketable crop that has wide adaptability with higher return and food production, provides a source for low cost nutrition and energy per unit area and time. The area and production under potato has increased rapidly in Asia against a declining trend in western countries. Developing countries accounts for $44 \%$ of the total potato production in the world (Paul Khurana and Naik, 2003). A significant increase in potato pro- duction in Asia over the last 25 years was mainly in the irrigated sub-tropical plains, particularly in the Indo-Gangetic plains extending over parts of Pakistan, Nepal, India and Bangladesh. The majority of potato produced in India is in the Indo-Gangetic plains comprising of the states of Uttar Pradesh, West Bengal and Bihar. Rice and wheat are two staple crops of these areas and provide ample scope for inclusion of potato in the cropping system (Saha et. al., 2002).

The state of West Bengal has witnessed a

\footnotetext{
* Corrisponding Author: Tel.: +91 9450346890; Fax +91 5422368465. E-mail address: amitavabhu@gmail.com
} 
five-fold increase in potato growing area in the last 25 years, the area, production and productivity have registered an increment at the rate of 5.22, 7.58 and 2.24 per cent per annum respectively (Anonymous, 2000). Presently, it heads the list of Indian states in terms of productivity and stands second in area and production. The major potato growing districts of the state are East Midnapore, West Midnapore, Hooghly, and Burdwan; which collectively share more than a quarter of country's total potato production.

The production cost is very high in potato as compared to cereals. The seed share is about $40-50 \%$ of total production cost of potato and is associated with such a quick degeneration by viruses and oil borne diseases. According to Waterhouse (1999) seed material alone shared $10.6 \%, 14.5 \%, 34.2 \%, 35.6 \%$ and $43.6 \%$ of the total cost of potato production in USA, Australia, Thailand, Indonesia and India respectively. True Potato Seed (TPS) is a captivating technological alternative that offers farmers an option to overcome the above-mentioned weakness of clonally propagated tuber as a source of planting material. Besides, being a hybrid, TPS expresses vigour for different yield components resulting in increase in yield with quality tuber

The production of small sized seedling tubers (clone) from TPS seedling has been considered important from the standpoint of quality and quantity of seedling tuber requirement in potato cultivation. It will reduce the cost of seedling tuber compared to conventionally practiced seed tuber cost in potato cultivation. Since, $5 \mathrm{~g}$ size of hybrid seedling tubers are potential enough to produce high tuber yield, comparable or even better than $50 \mathrm{~g}$ normal seed tuber under West Bengal condition, the use of small sized hybrid seedling tubers developed from TPS seedlings opens up a new horizon in potato cultivation (Das, 1998). The alternate means of utilizing the TPS for production of table potato by transplanting the seedling is yet to be explored to its fullest extent. During the last two decades, extensive research carried out throughout the world brought the fact that use of TPS for the production of ware potatoes reduced the cost of production and increased net profit to the farmers. India has already taken a lead in the development of TPS technology through concerted efforts of the Central Potato Research Institute, Shimla and the International Potato Center, Peru. The target areas viz. West Bengal, Karnataka, Maharastra, Madhya Pradesh, Orissa, Gujarat, South Bihar and the NE region have been identified for this technology.

In TPS, dates of establishment and crop spacing offers wide range of variability in yield attributing characters and productivity of the crop. Hence, the present investigation was conducted during the rabi (winter) season of 200102 and 2002-03 in the same experimental site at Potato Research and Seed Multiplication Farm, Anandapore, Paschim Medinipore, West Bengal (latitude $-22.653^{\circ} \mathrm{N}$, longitude $-87.458^{\circ} \mathrm{E}$ ) to study the effect of dates of transplanting and spacing on yield attributing character, productivity and economics of potato cultivation through true potato seed (TPS) technology.

\section{Materials and methods}

The experimental plot was well drained and leveled and it had sandy loam soil, which belongs to order alfisol. The chemical analysis of top

Table 1. Physico-chemical properties of the experimental soil $(0-30 \mathrm{~cm}$ depth).

\begin{tabular}{|c|c|c|}
\hline Parameters & Value & Methods followed \\
\hline pH (1:2.5 Soil water ratio) & 6.7 & Glass electrode pH meter (Jackson, 1973) \\
\hline Electrical conductivity $\left(\mathrm{ds} \mathrm{m}^{-1}\right)$ & 0.15 & (Jackson, 1973) \\
\hline Organic carbon $(\%)$ & 0.42 & (Jackson, 1973) \\
\hline Available $\mathrm{P}_{2} \mathrm{O}_{5}\left(\mathrm{~kg} \mathrm{ha}^{-1}\right)$ & 46 & Bray's method (Jackson, 1973) \\
\hline Available $\mathrm{K}_{2} \mathrm{O}\left(\mathrm{kg} \mathrm{ha}^{-1}\right)$ & 99 & Flame photometer method (Jackson, 1973) \\
\hline Total N (\%) & 0.04 & Modified microjheldal method (Jackson, 1973) \\
\hline Sand $(\%)$ & 20.8 & International pipette method \\
\hline Silt $(\%)$ & 61.2 & International pipette method \\
\hline Clay $(\%)$ & 18.0 & International pipette method \\
\hline Bulk Density $\left(\mathrm{kg} \mathrm{m}^{-3}\right)$ & 1.35 & (Jackson, 1973) \\
\hline
\end{tabular}



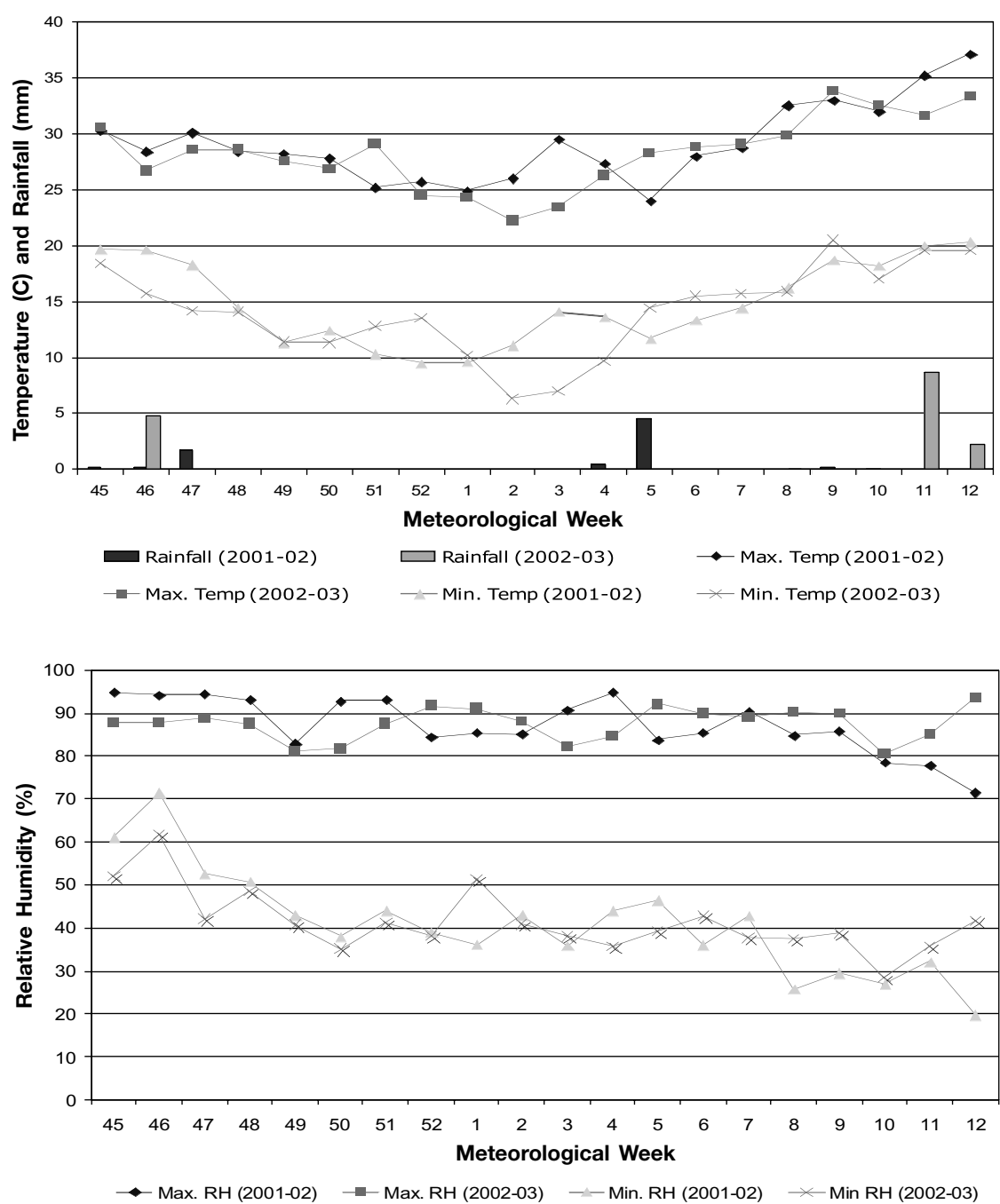

Figure 1a. Temperature and rainfall at the experimental station during two potato growing season (2001-02 and 2002-03).
Figure 1b. Relative humidity at the experimental station during two potato growing season (2001-02 and 2002-03). thirty-centimeter soil showed that it was slightly acidic in reaction, medium in available phosphorus and low in both total nitrogen and available potassium. All weather parameters during the crop growing period were under normal range for the region during both the years under study (Fig. 1a and 1b).

The experiment was laid out in 'split plot design' with three dates of transplanting i.e. $3^{\text {rd }} \mathrm{De}$ cember, $11^{\text {th }}$ December, $19^{\text {th }}$ December (during both years) as main-plot treatments and six plant population/ spacing (i.e. $40 \times 10 \mathrm{~cm}, 40 \mathrm{x}$ $15 \mathrm{~cm}, 50 \times 10 \mathrm{~cm}, 50 \times 15 \mathrm{~cm}, 60 \times 10 \mathrm{~cm}, 60$ $\mathrm{x} 15 \mathrm{~cm}$ ) as sub-plot treatments with three replications. Size of each sub-plot was $6.0 \mathrm{~m} \times 3.0 \mathrm{~m}$. Data were submitted to ANOVA; mean were compared by using the t-test statistic $(\mathrm{p}=0.5)$.

Raised beds of $1 \mathrm{~m}$ width at the top and 1.5 $\mathrm{m}$ at the bottom and $10 \mathrm{~m}$ length were prepared for TPS nursery. Substrate for the seed bed was prepared by mixing sterilized soil and well rotten farm yard manure in 1:1 ratio. Fertilizers at $5 \mathrm{~g} \mathrm{~N}, 8 \mathrm{~g} \mathrm{P}_{2} \mathrm{O}_{5}$ and $10 \mathrm{~g} \mathrm{~K}_{2} \mathrm{O} / \mathrm{m}^{2}$ application were added in the substrate and mixed well. Phorate granules at $1.5 \mathrm{gm}^{-2}$ application was given to prevent ants attack. Over this substrate, 2-3 cm thick layer of sieved FYM were given to make the seed bed of about $10 \mathrm{~cm}$. TPS (variety HPS I/13) seeds treated with $5 \mathrm{~g} \mathrm{GA}_{3}$ are sown at $0.5 \mathrm{~cm}$ depth in raised nursery beds prepared to good tilt with finely powdered dry cow dung in rows at $10 \mathrm{~cm}$ apart \& provide shed. Light irrigation was applied initially at least thrice in a day to keep the bed moist. Four to five foliar spray of $0.1 \%$ urea was given at an interval from 15th day after sowing on alternate 
days till the seedlings are ready for transplanting (25 to 28 days) with 3 to 4 leaf stage. Care have be taken against termite and damping-off.

Main field for the experiment was prepared by deep ploughing, 2-3 harrowing and planking. Broadcasting of FYM at $20 \mathrm{t} / \mathrm{ha}$ application, half dose of nitrogen and full dose of $\mathrm{P}_{2} \mathrm{O}_{5}$ and $\mathrm{K}_{2} \mathrm{O}$ i.e. $50-100-100 \mathrm{~kg} / \mathrm{ha}$ respectively was done at the last round of field preparation. Crop lines of $2 \mathrm{~cm}$ depth with varied spacing in East- West direction was prepared. Seedlings were transplanted with utmost care in the afternoon only to reduce mortality. Two irrigations were given to the crop everyday by a rose can till 1 week. Thereafter, when furrows were formed, those were irrigated every fourth day till the seedlings were established. Later, the frequency of irrigation was reduced to once in 8-10 days as per the crop demand. Top dressing of $\mathrm{N}$ at $50 \mathrm{~kg} / \mathrm{ha}$ applications was done just prior to earthing up after one month of transplanting. Weeding was done manually after 15 and 30 days of transplanting. No diseases and pests problems were reported in the experimental site. However, two prophylactic spray of Indophil-M-45 fungicide were given in the plot. After 80 days of transplanting, dehaulming of the crop was done separately for three dates of planting and record of the foliage yield was taken for calculation of harvest index. Harvesting from individual plot was carried out 10 days after dehaulming. Harvesting from the net plot (excluding border rows) was done with the help of spade and weight of two grades of produce viz. marketable tuber and seedling tuber were recorded and computed as $\mathrm{t} / \mathrm{ha}$. During the experimentation, different yield attributing characters were studied as follows:

Harvest Index: The harvest index of potato crop raised from TPS seedlings was computed from tuber yield and total biomass yield recorded at 80 DAT (during dehaulming).

Tuber number per plant: Number of tubers collected from five plants per plot was counted at 75 DAT and it was converted into number of tubers per plant.

Tuber weight per plant: Fresh weight of tubers of five plants per plot was recorded at 75 DAT and converted in weight $(\mathrm{g})$ of tubers per plant.

Marketable tuber yield: After harvesting of the crop, potato tubers were sorted in two grades: marketable tuber and seedling tuber. Individual tuber weighing $20 \mathrm{~g}$ and above are referred to as marketable tuber or ware potato and expressed as $\mathrm{t} \mathrm{ha}^{-1}$.

Seedling tuber yield: Tuber weighing less than $20 \mathrm{~g}$, kept for next year planting are denoted as the seedling tuber or tuberlet and expressed as $\mathrm{t} \mathrm{ha}^{-1}$.

Total tuber yield: Weights of both marketable and seedling tubers were summed up to obtain the total tuber yield per plot and expressed as $\mathrm{tha}^{-1}$.

\section{Results and discussions}

Interaction of dates of transplanting and crop spacing did not show any significant effect on harvest index; number and weight of tuber per plant; ware potato and tuber let yield and total productivity of the crop.

\section{Harvest Index}

Early transplanting showed its superiority over intermediate and late transplanting in respect of recording harvest index of potato in the year 2001-02 (Tab. 2). Late transplanted crop registered significantly lower harvest index than that of other dates of transplanting during the same year. But in 2002-03, different dates of transplanting did not show any significant effect on influencing the harvest index of the crop.

Wide spacing was found beneficial in increasing harvest index of potato. Out of six different spacing combinations, $60 \times 15 \mathrm{~cm}$ spacing recorded the maximum harvest index which was at par with $50 \times 15 \mathrm{~cm}$ in 2001-02 and with all other treatments excluding the most narrowly spaced $(40 \times 10 \mathrm{~cm}$ ) crop in 2002-03 (Tab. 2). Difference in harvest index was significant only between the highest and the lowest spaced crop during the second year of study. Widely spaced crop receiving the advantage of greater light, water and nutrients effectively engage in photosynthesis and it's partitioning into the economic organ (tuber), which in turn increased the harvest index.

\section{Number of tubers per plant}

Number of tubers per plant is an important yield component in determining the total yield of potato. The highest number of tubers per plant was recorded in early transplanted crop 
Table 2. Effect of date of establishment and crop geometry on harvest index, tuber number and tuber weight per plant.

\begin{tabular}{|c|c|c|c|c|c|c|}
\hline \multirow[t]{2}{*}{ Particulars } & \multicolumn{2}{|c|}{ Harvest index } & \multicolumn{2}{|c|}{ Tuber number/ plant } & \multicolumn{2}{|c|}{ Tuber weight (g. plant ${ }^{-1}$ ) } \\
\hline & 2001-02 & $2002-03$ & 2001-02 & $2002-03$ & $2001-02$ & $2002-03$ \\
\hline \multicolumn{7}{|l|}{ Date } \\
\hline December 3 & 49.89 & 49.55 & 7.00 & 7.72 & 100.61 & 111.51 \\
\hline December 11 & 47.15 & 50.02 & 6.31 & 6.17 & 80.75 & 91.00 \\
\hline December 19 & 41.97 & 45.09 & 5.40 & 5.12 & 62.08 & 69.84 \\
\hline $\mathrm{CD}(\mathrm{P}=0.05)$ & 2.16 & NS & 0.49 & 0.72 & 10.02 & 11.75 \\
\hline \multicolumn{7}{|l|}{ Spacing } \\
\hline $40 \times 10 \mathrm{~cm}$ & 43.56 & 46.33 & 6.43 & 6.51 & 74.44 & 86.05 \\
\hline $40 \times 15 \mathrm{~cm}$ & 46.92 & 47.50 & 6.32 & 5.90 & 83.58 & 89.24 \\
\hline $50 \times 10 \mathrm{~cm}$ & 44.60 & 47.73 & 6.11 & 6.52 & 75.01 & 88.15 \\
\hline $50 \times 15 \mathrm{~cm}$ & 47.72 & 48.44 & 6.17 & 6.81 & 84.30 & 93.06 \\
\hline $60 \times 10 \mathrm{~cm}$ & 45.43 & 48.23 & 6.54 & 6.23 & 80.44 & 89.81 \\
\hline $60 \times 15 \mathrm{~cm}$ & 49.78 & 51.11 & 5.81 & 6.10 & 89.13 & 98.67 \\
\hline $\mathrm{CD}(\mathrm{P}=0.05)$ & 2.83 & 4.21 & NS & NS & 5.60 & 4.59 \\
\hline
\end{tabular}

* CD: Critical Difference.

and that was significantly superior to the other dates of transplanting during both the years (Tab. 2). This was mainly due to engagement of higher LAI in photosynthesis and its better partitioning into the sink, which in turn helped in producing greater number of tubers per plant in comparison to late transplanted crop. Crop transplanted on December 11 also recorded significantly greater number of tubers than that of late transplanted crop.

Different spacing combinations did not produce any significant differences in recording tuber number per plant during both of the years under study (Tab. 2). This indicated that crop geometry did not have much effect on enhancing the tuber formation in TPS crop. Weirsema (1986) also found that crop geometry had very little effect on increasing the number of tubers per plant.

\section{Weight of tubers per plant}

Date of establishment showed significant and positive influence on tuber development in potato (Tab. 2). Early transplanted (December 3) crop produced significantly higher tuber weight per plant as compared to that of the intermediate (December 11) and late (December 19) transplanted crops during both the years. Similarly intermediate transplanted crop had also registered significantly greater weight of tuber per plant than that of late transplanted crop during both years under study. The results are in conformity with the findings of Weirsema (1986).

Unlike tuber number, tuber weight per plant was positively and significantly influenced by crop geometry (Tab. 2). Widely spaced $(60 \times 15$ $\mathrm{cm})$ crop recorded maximum weight of tuber per plant, which remained at par only with the crop spaced at $50 \times 15 \mathrm{~cm}$ and $40 \times 15 \mathrm{~cm}$ during first year (2001-02) of study. Tuber weight per plant gradually decreased as the crop spacing decreased and thus the crop at close spacing $(40 \times 10 \mathrm{~cm}$ and $50 \times 10 \mathrm{~cm})$ recorded lower weight of tuber per plant as compared to other spacing under this investigation. This might be attributed to the lesser plant to plant competition for light, water and nutrient in widely spaced crop.

\section{Marketable tuber yield}

Early transplanted crop recorded significantly higher yield of marketable tubers than those of intermediate transplanted crop during 2001-02 and late transplanted crop during both the years (Tab. 3). Intermediate transplanted crop also registered greater yield of marketable tubers than that of late transplanted crop during both the years. Late transplanting, thus, produced the lowest quantity of marketable tubers under this study. This might be due to poor growth of the late transplanted crop that exposed to low temperature condition from the beginning. Similar observations were also reported by Naskar et al., 2003.

The highest yield of marketable tubers was recovered from the crop spaced at $50 \times 10 \mathrm{~cm}$ but was statistically at par with that at $40 \times 10$ $\mathrm{cm}$ spacing during both the years (Tab. 3 ). The 
Table 3. Effect of date of establishment and crop geometry on seedling tuber yield, marketable tuber yield and total tuber yield $\left(\mathrm{t} \mathrm{ha}^{-1}\right)$.

\begin{tabular}{|c|c|c|c|c|c|c|}
\hline \multirow[t]{2}{*}{ Particulars } & \multicolumn{2}{|c|}{ Marketable tuber } & \multicolumn{2}{|c|}{ Seedling tuber } & \multicolumn{2}{|c|}{ Total yield } \\
\hline & 2001-02 & $2002-03$ & 2001-02 & 2002- 03 & 2001-02 & $2002-03$ \\
\hline \multicolumn{7}{|l|}{ Date } \\
\hline December 3 & 14.39 & 15.59 & 5.14 & 5.80 & 19.53 & 21.39 \\
\hline December 11 & 11.23 & 13.29 & 4.65 & 5.72 & 15.88 & 19.02 \\
\hline December 19 & 7.78 & 10.01 & 4.04 & 4.86 & 11.82 & 14.87 \\
\hline $\mathrm{CD}(\mathrm{P}=0.05)$ & 1.77 & 2.48 & 0.51 & 1.69 & 1.89 & 3.38 \\
\hline \multicolumn{7}{|l|}{ Spacing } \\
\hline $40 \times 10 \mathrm{~cm}$ & 12.43 & 14.78 & 6.61 & 8.01 & 19.04 & 22.79 \\
\hline $40 \times 15 \mathrm{~cm}$ & 11.26 & 13.27 & 4.76 & 5.03 & 16.01 & 18.30 \\
\hline $50 \times 10 \mathrm{~cm}$ & 13.71 & 16.06 & 3.49 & 4.79 & 17.20 & 20.84 \\
\hline $50 \times 15 \mathrm{~cm}$ & 9.50 & 11.28 & 4.40 & 4.29 & 13.90 & 15.57 \\
\hline $60 \times 10 \mathrm{~cm}$ & 11.10 & 12.46 & 4.09 & 5.60 & 15.19 & 18.06 \\
\hline $60 \times 15 \mathrm{~cm}$ & 8.81 & 9.96 & 4.32 & 5.03 & 13.13 & 14.99 \\
\hline $\mathrm{CD}(\mathrm{P}=0.05)$ & 1.41 & 2.69 & 1.32 & 2.71 & 1.38 & 2.62 \\
\hline
\end{tabular}

* CD: Critical Difference.

yield of marketable tubers gradually decreased with the increase of crop spacing. This might be due to the higher photosynthetic efficiency per unit area in closely spaced crop. Quadri et al., (1998) also noticed that higher intra- row spacing gave maximum yield of large sized tubers ('A' grade), but less yield of total tubers and vice versa. Majumdar and Agrawal (2000), however, noted that HPS I/13 produced higher marketable tuber yield at wider spacing (60 x $20 \mathrm{~cm}$ ).

\section{Seedling tuber yield}

During the first year, early and intermediate transplanted crops produced significantly higher seedling tuber yield than the late transplanted one (Tab. 3). During the second year, the seedling tuber yield, however, did not vary much among the different dates of transplanting though seedling tuber yield showed a tendency of decline due to late transplanting. As seedling tubers were small grade tubers and late transplanted crop usually bore more of small sized tubers, thus it nullified the effect of early transplanting on seedling tuber yield.

Close planted crop produced significantly higher seedling tuber yield than other crop spacing during the first year of study while during the second year, it produced at par yield with that of plant spaced at $60 \times 10 \mathrm{~cm}$ spacing (Tab. $3)$. Other crop spacing did not show much variation in seedling tuber yield among them during both the years.

\section{Total tuber yield}

Maximum tuber yield was obtained from early transplanted crop, which was significantly higher than other dates of transplanting during the first year. But during the second year, tuber yield between the early and intermediate transplanted crops did not vary significantly under this study (Tab. 3). Delay in transplanting resulted in poor growth of the crop, which in turn decreased the tuber bulking rate and thus recorded low tuber yield by late transplanted crop.

Densely populated crop $(40 \times 10 \mathrm{~cm})$ recorded the highest tuber yield, which was significantly superior to all other treatments during both the years except at $50 \times 10 \mathrm{~cm}$ in the second year, where both spacing produced tuber yield at par with each other (Tab. 3). Tuber yield obtained from the crop oriented at $60 \times 10 \mathrm{~cm}$ was at par with that at $40 \times 15 \mathrm{~cm}$ and $50 \times 15$ $\mathrm{cm}$ but showed a significant yield improvement over the crop transplanted at $60 \times 15 \mathrm{~cm}$ during both the years. In short duration crop like potato, plant density plays an important role on crop growth and productivity particularly under short and mild winter condition in West Bengal. Here, high density crop covers the field early by promoting foliage growth and thus has an advantage over the low density crop in recording higher tuber bulking rate, which in turn helped in producing greater tuber yield. The result corroborates the findings of Upadhya et al. (1990), Singh (1994) and Veerana et al. (1997). 
Table 4. Cost of cultivation of potato raised from TPS hybrid at different dates of establishment and crop geometry.

\begin{tabular}{|c|c|c|c|c|c|c|c|}
\hline \multirow[t]{3}{*}{ Particulars } & \multirow{2}{*}{\multicolumn{2}{|c|}{$\begin{array}{l}\text { Nursery management } \\
\text { (Euro/ha) }\end{array}$}} & \multicolumn{3}{|c|}{ Main field management (Euro/ha) } & \multirow{2}{*}{\multicolumn{2}{|c|}{$\begin{array}{c}\text { Total cost of production } \\
\text { (Euro/ha) }\end{array}$}} \\
\hline & & & \multicolumn{2}{|c|}{ Labour cost } & \multirow{2}{*}{ Other inputs } & & \\
\hline & Seed & $\begin{array}{l}\text { Seedling } \\
\text { raising }\end{array}$ & 2001-02 & $2002-03$ & & 2001-02 & $2002-03$ \\
\hline \multicolumn{8}{|l|}{ Date } \\
\hline 3-Dec & 37 & 107 & 218 & 228 & 284 & 646 & 656 \\
\hline 11-Dec & 37 & 107 & 203 & 216 & 284 & 631 & 644 \\
\hline 19-Dec & 37 & 107 & 185 & 199 & 284 & 613 & 627 \\
\hline \multicolumn{8}{|l|}{ Spacing } \\
\hline $40 \times 10 \mathrm{~cm}$ & 54 & 107 & 238 & 254 & 284 & 683 & 699 \\
\hline $40 \times 15 \mathrm{~cm}$ & 36 & 107 & 202 & 212 & 284 & 629 & 639 \\
\hline $50 \times 10 \mathrm{~cm}$ & 43 & 107 & 216 & 232 & 284 & 650 & 666 \\
\hline $50 \times 15 \mathrm{~cm}$ & 28 & 107 & 184 & 190 & 284 & 603 & 609 \\
\hline $60 \times 10 \mathrm{~cm}$ & 36 & 107 & 199 & 211 & 284 & 626 & 638 \\
\hline $60 \times 15 \mathrm{~cm}$ & 24 & 107 & 174 & 183 & 284 & 589 & 598 \\
\hline
\end{tabular}

Economics of potato production from TPS hybrid

Cost of production for different components were studied separately and found that nursery management, main field management and labour comprised of about $23 \%, 42-48 \%$ and $29-35 \%$ of the total cost of production respectively (Tab. 4). Cost of production of early transplanted (December 3) crop was higher because of higher tuber yield, which engaged more labour per unit area. As such, the lowest cost of production was recorded in December 19 transplanted crop during both the years under study. Closely spaced crop, which yielded more tuber yield than other spacing, also recorded more cost of cultivation of potato from the TPS seedlings. The highest cost of production to the tune 683 euros in 2001-02 and 699 euros in 200203 was recorded in the crop transplanted at 40 x $10 \mathrm{~cm}$. While, the lowest cost of production was registered by the crop grown at the widest spacing $(60 \times 15 \mathrm{~cm})$.

Net profit and return per rupee investment varied considerably among different dates of establishment of TPS seedling and crop geometry (Tab. 5). Early transplanted crop paid higher gross profit, net profit and return per euro invested, which were sharply declined due to delay in transplanting. Densely populated crop (40 $\mathrm{x} 10 \mathrm{~cm}$ ) gave the highest net profit and return

Table 5. Economics of potato production raised from TPS hybrid at different dates of establishment and crop geometry.

\begin{tabular}{|c|c|c|c|c|c|c|c|c|}
\hline \multirow[t]{2}{*}{ Particulars } & \multicolumn{2}{|c|}{$\begin{array}{l}\text { Production cost } \\
\text { (Euro/ha) }\end{array}$} & \multicolumn{2}{|c|}{$\begin{array}{l}\text { Gross profit } \\
\text { (Euro/ha) }\end{array}$} & \multicolumn{2}{|c|}{$\begin{array}{l}\text { Net profit } \\
\text { (Euro/ha) }\end{array}$} & \multicolumn{2}{|c|}{$\begin{array}{l}\text { Return per Euro } \\
\text { investment (Euro) }\end{array}$} \\
\hline & 2001-02 & $2002-03$ & 2001-02 & $2002-03$ & $2001-02$ & $2002-03$ & 2001-02 & $2002-03$ \\
\hline \multicolumn{9}{|l|}{ Date } \\
\hline 3-Dec & 646 & 656 & 1877 & 2069 & 1231 & 1413 & 1.9 & 2.2 \\
\hline 11-Dec & 631 & 644 & 1562 & 1882 & 931 & 1238 & 1.5 & 1.9 \\
\hline 19-Dec & 613 & 627 & 1207 & 1501 & 594 & 875 & 1.0 & 1.4 \\
\hline \multicolumn{9}{|l|}{ Spacing } \\
\hline $40 \times 10 \mathrm{~cm}$ & 683 & 699 & 1952 & 2343 & 1269 & 1644 & 1.9 & 2.4 \\
\hline $40 \times 15 \mathrm{~cm}$ & 629 & 639 & 1581 & 1775 & 952 & 1136 & 1.5 & 1.8 \\
\hline $50 \times 10 \mathrm{~cm}$ & 650 & 666 & 1574 & 1951 & 924 & 1285 & 1.4 & 1.9 \\
\hline $50 \times 15 \mathrm{~cm}$ & 603 & 609 & 1392 & 1511 & 790 & 902 & 1.3 & 1.5 \\
\hline $60 \times 10 \mathrm{~cm}$ & 626 & 638 & 1467 & 1800 & 841 & 1163 & 1.3 & 1.8 \\
\hline $60 \times 15 \mathrm{~cm}$ & 589 & 597 & 1328 & 1523 & 739 & 926 & 1.3 & 1.6 \\
\hline
\end{tabular}


per euro invested. This might be due to the higher plant population that contributed to the tuber yield of the crop. Closely spaced crop also resulted in the production of higher quantity of seedling tuber, which fetched more prices in the market ( 0.15 euros per $\mathrm{kg}$ ) than the ware potato (0.08 euros per $\mathrm{kg}$ ). Net return and return per euro invested went on declining with the increase in crop spacing.

\section{Conclusions}

Different dates of establishment of TPS hybrid (HPS-I/13) showed significant effect on various growth attributes recorded under this study. The highest number and weight of tubers per plant was recorded when the crop was transplanted early. This resulted into maximum tuber yield in early transplanted crop, which was succeeded by the moderately late (December 11) transplanted crop. The lowest tuber yield was obtained from the late (December 19) established crop. Accordingly maximum net profit and return per rupee invested was recorded from the early established crop during both the years under study.

Crop spacing did not show any significant effect on tuber number per plant. However, tuber weight per plant increased with increasing crop spacing to register the highest value at 60 x $15 \mathrm{~cm}$. But as the number of plant per unit area reduced with wider spacing, the magnitude of total tuber yield was higher in highly populated crop having narrow crop spacing. Out of two grades of the produce, seedling tuber yield was significantly higher only in the crop transplanted at $40 \times 10 \mathrm{~cm}$, while highest marketable tuber yield was registered in the crop spaced at $50 \times 10 \mathrm{~cm}$ during both the years under study.

From the above results, it may be concluded that early transplanting (December 3) of TPS seedling is conducive for obtaining higher tuber yield and greater economic return. Narrow spacing $(40 \times 10 \mathrm{~cm})$ needs to be considered not only for increasing the total tuber yield of potato but also for the production of high value, disease-free seedling tubers to be used for next year planting.

\section{References}

Anonymous 2000 Estimates of area and production of principal crops in West Bengal. 1999-2000. Evaluation Wing, Directorate of Agriculture, Government of West Bengal.

Das D. 1998. Studies on growth, development and yield of tuberlet produced from seedlings of true potato seed. M.Sc. thesis submitted to Bidhan Chandra Krishi Viswavidyalaya, 54.

Majumdar B., Agrawal S.S. 2000. Agro-techniques of potato production using True Potato Seed for low productivity areas under Indian condition. Proceedings of the African Potato Association Conferencel, 5:77-81.

Naskar B., Bardhan Roy S.K., Sen D. 2003. Effect of date of transplanting on tuber yield of TPS seedlings in the main field. Annual Report, 2002-2003. Economic Botanist - III, Directorate of Agriculture. Govt. of West Bengal, 33-34.

Paul Khurana S.M., Naik P.S. 2003. The Potato: an overview. In: Paul Khurana S.M., Minhas J.S., Pandey S.K. (eds.): The Potato Production and Utilization in Sub-tropics, 1-14. Mehta Publication, New Delhi.

Quadri S.J., Dhoble M.V., Karle A.S. 1998. Effect of inter and intra row spacing of transplanted seedlings on yield of potato. Journal of the Indian Potato Association, 25, 1-2:83-85.

Saha N.K., Bardhan Roy S.K., Kadian M.S., Walker T., Illangantileke S.G., Verma V.S. 2002. Potato in rice based cropping systems and analysis of associated constraints: A study in West Bengal, India. Journal of the Indian Potato Association, 29, 1-2:19-25.

Singh K. 1994. Standardizing optimum spacing for transplanting True Potato Seed in North-East Hill Region. Journal of the Indian Potato Association, 21, 1-2:154156.

Upadhyay M.D., Thakur K.C., Kadian M.S. 1990. Standardization of TPS Agronomy. In: Gour P.C. (ed.): Commercial Adoption of TPS technology - Problems and Prospects, 36-39. CPRI, Shimla.

Veerana H.K., Khalak A., Krishnamurthy N., Mudalagiriappa I., Khalak A. 1997. Effect of spacing and fertilizer levels on ware potato yield and quality of tubers obtained through 'TPS' seedlings. Indian Agriculturist, 41, 1:31-36.

Waterhouse P. 1999. The use and benefits of Technituber $^{\circledR}$ seed in Asian potato cultivation. Proceedings of the Global Conference on Potato, New Delhi.

Weirsema S.G. 1986. The effect of density on tuber yield in plants grown from TPS in seed beds during two contrasting seasons. American Potato Journal, 63, 9:465-472. 